\title{
Students' acceptance and readiness for E-learning in Northeastern Thailand
}

Open Access

\author{
Anchalee Ngampornchai ${ }^{*}$ (i) and Jonathan Adams
}

\author{
* Correspondence: \\ angampornchai@fullerton.edu \\ University Extended Education \\ California State University, Fullerton, \\ CA, USA
}

\begin{abstract}
The study explored student readiness for online learning in the Northeast of Thailand, using the Unified Theory of Acceptance and Use of Technology (UTAUT). The survey also explored students' self-regulation, computing devices ownership, and level of familiarity with education-related technologies. The responses imply that students have a slightly positive perception toward e-learning. They use mobile technologies extensively, and have experience using social media; but are unfamiliar with other collaborative e-learning tools. A discussion includes recommendations for cultural context and the design of e-learning in Thailand.
\end{abstract}

Keywords: Acceptance of E-learning, Online education, Northeast Thailand, Readiness for e-learning, UTAUT

\section{Introduction}

In Thailand, like many developing countries, e-learning and Information Communication Technology (ICT) have become an important part of a national effort to improve public education. On one hand, Thai educators hope that e-learning will provide a pathway to education for students who are unable to access higher education; on the other, it is a necessary enhancement for the country to become more competitive among the ASEAN neighbors (Khaopa, 2012; Saowapon, Laohajaratsaeng, Thammajinda, \& Singharajwarapan, 2001). Currently, 31 higher education institutions in Thailand have learning management systems, 23 of which are public institutions (Rueangprathum, Philuek, \& Fung, 2009). The Thai government has supported such efforts by providing funding for infrastructure projects. For example, the Thai government has established Internet services for all schools and postsecondary institutions (SchoolNet and UniNet) and developed an e-learning portal called Thailand Cyber University (Saekow \& Samson, 2011; Saengpassa, 2013).

The Northeastern districts in Thailand have been recognized as the most underdeveloped region in the country (Carsten \& Temphairojana, 2013), where average education achievement ranges between 6.7 and 9 years (Decade 2020, 2015). Online education or e-learning is uniquely suited to adult education as participants can access their lessons, communicate with the class or teacher, and collaborate with others wholly online. The Thai government has supported the use of digital technologies to provide rural regions access to higher education and has made many improvements to strengthen

(C) 2016 The Author(s). Open Access This article is distributed under the terms of the Creative Commons Attribution 4.0 International License (http://creativecommons.org/licenses/by/4.0/), which permits unrestricted use, distribution, and reproduction in any medium, provided you give appropriate credit to the original author(s) and the source, provide a link to the Creative Commons license, and indicate if changes were made. 
infrastructure and university network capacity. In spite of many improvements, online education still faces policy, standards and administrative structure challenges.

In practice, researchers have noted goal setting, limited training and support (for educators and students), inconsistent Internet quality, and Thai pedagogy as noteworthy obstacles to developing an e-learning program (Pagram \& Pagram, 2006; Siritongthaworn, Krairit, Dimmitt, \& Paul, 2006). Diffusion research examines characteristics (i.e. relative advantage, compatibility, complexity, trialability, and observability) at some point in time as technologies are adopted (Rogers, 1983). New technologies and systems are often studied to learn how to make the new system or technology more usable, or compatible with current practices.

The current study examines undergraduate student perceptions of e-learning and awareness of new learning technologies in a rural Thai community. As noted, e-learning innovation research includes the study of acceptance of online learning after an innovation has been adopted for classroom use. Such research also includes research that examines the perceived consequences of adopting an innovation before the innovation is adopted. The current research examines the perceived consequences of adoption by a group of undergraduate students attending a regional campus located in the Northeastern region of Thailand to identify specific characteristics that affect the adoption of e-learning (Adams, 2008; Lee, Hsieh, \& Hsu, 2011; Park, 2009). We devised a survey modeled on the unified theory of acceptance of technology (Venkatesh, Morris, Davis, \& Davis, 2003), a framework of multiple theories that allow for sophisticated analysis of factors that may produce uncertainty about adopting the innovation. The results offer some insights which may lead to more effective policies or e-learning strategies.

\section{Literature review}

\section{E-learning in developing countries}

For many developing countries, e-learning is considered a solution to the increasing demand for higher education. In Pakistan, online education is promoted as "education for all" as it aims to reach out to students living too far from the cities and unable to afford the cost of conventional higher education (Iqbal \& Ahmad, 2010). In Botswana, e-learning solves the problems of large classrooms, increasing enrollment, and limited staff (Ikpe, 2011). The author stated that the decision to integrate e-learning "was not borne out of a desire to join an elite club of technologically savvy universities but was out of the need to solve practical problems related to access and the quality of learning experiences" (p. 84). E-learning is also expected to help improving students' computer literacy - the skill needed in the current workforce (Addah, 2012; Akhu-Zaheya, Khater, Nasar, \& Khraisat, 2011; Bediang, et al., 2013).

Numerous challenges were discussed with regard to promoting online education in developing countries. A survey to staff and students from three Nigerian universities revealed that the low acceptance of e-learning was due to the low awareness level, low computer literacy level, unreliable platform and Internet services, and the high cost of implementation (Folorunso, Ogunseye, \& Sharma, 2006). Similarly, obstacles faced by Pakistani universities included infrastructure, students' limited access to computer, untrained instructors, and cultural beliefs. It was further challenging when schools have to translate English, as the predominant language in the online environment, into the 
local language of Urdu in order to reach wider learners (Iqbal \& Ahmad, 2010). Another study by Addah (2012) revealed that resistance to e-learning in Ghana came from the students' fear of isolation and computer illiteracy.

A number of studies focused on computer access, ownership, and computer skills, based on the assumption that these factors contribute to computer literacy that influences the adoption of e-learning. Bediang et al. (2013) conducted a survey to students in Cameroon and found that two-third of the students were not familiar with the concept of e-learning and that $17 \%$ of students did not own a personal computer. Most students who used the Internet had only basic email and Web search computer skills. In another study from Jordan, Akhu-Zaheya et al. (2011) found that most students did not own computers at home and for the most part, they used word processing, email, and web searching. The students with limited use of computer developed computer anxiety, which led to computer illiteracy.

Bhuasiri et al. (2012) explored critical success factors with e-learning experts (faculty, ICT experts, and researchers) in developing countries. The top four factors that emerged from the data as ranked by ICT experts were computer training, perceived usefulness, attitude toward e-learning, and computer self-efficacy. The top four factors, ranked by faculty, were perceived usefulness, attitude toward e-learning, program flexibility, and clear direction. The researchers concluded that people in developing countries are less familiar with technology and therefore are far more critical of e-learning.

While the existing research informed us about several challenges, few studies attempted to connect these shortcomings to users' acceptance of e-learning. As Moore and Benbasat (1991) argued, the potential adopters' perceptions of innovations were so critical for the success of the integration. In the next section, we outline the theoretic frameworks that influenced the design of the current research.

\section{Acceptance of E-learning}

A number of theoretic perspectives have influenced the development of survey instruments that are used to assess adoption (or acceptance) of a new technology. While each of the theoretic frameworks is rooted in the study of innovation adoption (e.g., Lee, et al., 2011), each has a different perspective. For example, Rogers' (1983) Diffusion of Innovation Theory proposes five characteristics of an innovation as: relative advantage, compatibility, complexity, trialability, and observability. Moore and Benbasat (1991) later developed an instrument based on Roger's theories and added two more constructs; voluntariness explains that the freedom to choose whether to use a technology should affect the willingness to adopt, and image is defined as "the degree to which use of an innovation is perceived to enhance one's image or status in one's social system” (p. 195).

Another widely-used model is the Technology Acceptance Model or TAM (Davis, Bagozzi, \& Warshaw, 1989). They adopt perceived usefulness and perceived ease of use as key variables that influence users' attitude, intention, and actual behavior to use a new technology. The basic tenet is that the users are more inclined to use a new technology if they think that it helps them do their job and is easy to use. A number of e-learning studies have used the TAM model. For example, Park (2009) attempted to predict students' intention to use the e-learning system in a Korean university. The researcher found that the TAM constructs were effective determinants of e-learning 
acceptance. Park reported that perceived usefulness and perceived ease of use had strong relationships with attitude, and at the same time, e-learning self-efficacy and subjective norm were strong predictors of intention to use e-learning.

Venkatesh et al. (2003) proposed the Unified Theory of Acceptance and Use of Technology (UTAUT). The UTAUT framework draws upon eight theoretic frameworks (e.g., Innovation Diffusion Theory, Technology Acceptance Model), which predict individual intentions to use and the behavior of technology usage from four constructs. A number of research studies have modeled questionnaires using the UTAUT framework. For example, Im, Hong, and Kang (2011) used this model to predict users' adoption of MP3 players and Internet banking systems in Korea and the United States. The researchers hypothesized that expectations for performance would have a greater impact on behavioral intention in cultures with lower power distance, more individualism, more masculinity, and lower uncertainty avoidance and that social norms would have a greater impact on user behavioral intention in cultures with higher power distance, less individualism, less masculinity, and higher uncertainty avoidance. Their work implies that cultural norms appear to have an influence on adoption decisionmaking in certain contexts. Similarly, in a study conducted on the adoption of blogs (Pardamean \& Susanto, 2012), effort expectancy and social influences were noted to play a role in the adoption of blogging technologies.

Kijsanayotina, Pannarunothaib, and Speedie (2009) used the UTAUT to evaluate factors that influence use of health Information technologies in Thai health centers. The researchers noted that uptake of the technologies was influenced by expectations of use, social influence and voluntariness. The researchers noted that individual perceives that important others believe he or she should use health IT. The construct contains a notion that an individual's behavior is influenced by the way in which one believes others will view him/her as a result of having used health IT. While there are several studies noting social influence as having a strong effect on adoption, there are others that make this dimension noteworthy but remains inconclusive.

\section{E-learning in Thailand}

While there are many positive signs, several challenges slow down the use of e-learning in Thailand. First, students reported having limited access to computer and that the Internet quality is inconsistent, especially at home (Siritongthaworn et al., 2006). Many students explained that they usually use computers at school where there is limited access time and many reported having difficulty accessing online materials due to the lack of appropriate software. Vate-U-Lan (2007) assessed e-learning connectivity of public secondary schools in and outside Bangkok and found the technology issues to be even worse. While all schools in Bangkok area reported that they were ready for e-learning, only $70.6 \%$ of schools outside of the city had the infrastructure and equipment to be defined as such. These schools outside Bangkok still have very limited access to the Internet and are using outdated computer systems.

In a survey to students in three public universities in Thailand, Teo, Luan, Thammetar, and Chattiwat (2011) found that the acceptance of e-learning was above average, and the students who tended to adopt e-learning were younger students with technology skills. Siritongthaworn et al. (2006) reported similar positive attitudes. Based on the interviews 
with universities' administrators, instructors, and students, the researchers found that online learning was viewed as convenient and efficient. The participants liked the fact that online learning can be used anytime and anywhere and e-learning helped to reduce the cost of printed materials. Despite these positive perceptions, the instructors had little or no experience with online teaching methodology and so they were pedagogically unprepared to use an online learning system.

Thai cultural values of collectivism and respect for authority also create barriers to the adoption of e-learning. The collectivistic value influences the habit of group work and collaboration. A respect-for-authority mentality cultivates passive learners who are used to receiving information from teachers and ask very few questions (Foley, 2005). The Thai learning environment that fosters rote learning contrasts sharply with the online education approach that relies on the learners' self-motivation and self-regulation. Pagram and Pagram (2006) vividly demonstrated this cultural contrast when they interviewed stakeholders including educators, administrators, ICT experts, parents, and adult students. The participants tended to believe that online education does not match well with Thai values. The authors stated, "The inability of e-learning to convey such constructs as respect for those older than oneself and seniority based upon position as well as working together for the benefit of the group rather than for individualistic aims were cited as cultural dangers" (p. 6).

The current study explores the perceptions of e-learning, where lessons, communication, and collaboration are facilitated online in a rural area of Thailand. It is important to note that this study is interested in the potential adopters' perceptions, as opposed to adopters' perceptions while using the technology. Our target participants are traditional students, enrolled in regular face-to- face classes. Accordingly, we asked the following exploratory research questions: What is the students' level of acceptance for e-learning? Is self-regulation related to the acceptance of e-learning? Does familiarity with computer technologies affect the students' acceptance of e-learning?

\section{Methods}

The current study utilized Moore and Benbasat's, TAM, and UTAUT models. Yet, as it is exploratory in nature, this study selected measurement items from these theories mainly for the purpose of learning about students' perception and attitude. The goal of this study does not include prediction of any future behavior. Following Davis, Bagozzi, and Warshaw (1989), perceived usefulness is defined as "the prospective user's subjective probability that using a specific application system will increase his or her job performance within an organizational context" (p. 985). Perceived ease of use refers to "the degree to which the prospective user expects the target system to be free of effort" (p. 985).

The UTAUT framework (Venkatesh, et. al., 2003) draws upon eight theoretic frameworks and assess technology usage using four constructs to predict intention and behavior of technology usage. Performance expectancy refers to the individuals' belief that using the tool will increase their performance. This construct derives from determinants including TAM's perceived usefulness. Effort expectancy is defined as the perception about the degree of ease when using the tool. Deriving from TAM's perceived ease of use, this construct is predicted to be salient determinant in the early stage of technology adoption. Social influence refers to "the degree to which an individual perceives that important others believe he or she should use the new system" (p. 451). It 
derives from TAM's subjective norm. Lastly, facilitating conditions refers to the perceived degree of organizational support for the use of the tool. That is, the intention to use a new technology is contingent upon one's perception of organizational support and guidance. Attitude is an indirect determinant within the UTAUT model. It refers to affective reaction or feeling of liking, joy, or pleasure associated with the use of technology.

\section{Participants}

The participants were undergraduate students in a small campus of a public university in the northeast of Thailand. The campus is located in a city of approximately 185,000 people. At the time of our data collection, the campus had approximately 180 students and 15 full and part-time instructors. The campus did not have online courses, nor did it have learning management system. The survey was distributed to 180 students, the entire student population on campus. Ninety eight questionnaires were returned. Surveys that were returned incomplete and duplicated were discarded, leaving a total of 84 usable questionnaires, a $47 \%$ response.

\section{Instrument and procedure}

A questionnaire was developed and consisted of four major parts: (1) demographics, (2) students' self-regulation, (3) acceptance of e-learning, and (4) familiarity with technology. The first part contained questions about demographics, ownership of computing devices, and Internet access. In part two, four 5-point Likert scale statements explored students' self-regulation. Pintrich (2000) stated that self-regulated learners are individuals who "set goals for their learning, and then attempt to monitor, regulate, and control their cognition, motivation, and behavior, guided and constrained by their goals and the contextual features of the environment" (p. 453). Oliver (2014) contended that self-regulatory behaviors include the ability to set goals, to effectively manage time, to solve problems on one's own, and to know when to seek advice from instructors. Based on these definitions, the four self-regulatory statements developed for this study focused on learning autonomy, goal setting, time management, and independent learning habit.

In part three, 18 items, on a 5-point scale, measure e-learning acceptance. Of these, 12 items were adapted from four constructs in the UTAUT model: performance expectancy (4 items), effort expectancy (4 items), attitude toward e-learning (3 items), and social influence (1 item). Another six items were adapted from Moore and Benbasat's (1991) constructs of image (4 items) and compatibility ( 2 items). We selected and modified these items with the close consultation with the local professors at the campus.

Modified from Son, Robb, and Charismiadji (2011), the last set of questions asked the students to report about their use of technology in frequency (from "never" to "everyday"). The technologies included word processing, spreadsheet, e-mail, search engines, Google drive, discussion forum, text chat, voice chat, video chat, photo-based websites, video-based websites, wiki, blogs, games, and social media. These technologies were selected as they are often utilized for online learning.

We first developed the questionnaire in English language. Then, we translated it into Thai language. The translation and back-translation were performed by three native Thai, two of whom are fluent in Thai and English languages. The questionnaire was distributed to students through Qualtrics, an electronic survey system. The request for 
participation was published on the campus's Facebook group. Then, the professors at the campus followed up by prompting students to participate during their face-to-face class time. Because some students did not have convenient access to the electronic survey, the classroom professors also circulated a paper-based questionnaire. The data were collected within 2 weeks between March and April of 2015.

The data were analyzed using the statistical software PSPP. In order to answer research questions, descriptive statistics were calculated. Pearson correlation test was performed to uncover correlations between variables and constructs. Factor analysis and Cronbach's alpha reliability test were used to explore and confirm construct validity.

\section{Results}

\section{Descriptive statistics}

All 84 respondents were undergraduate students, $77 \%$ female, $23 \%$ male. Ninety percent of the respondents were between 18-23 years old. Most were freshmen (40\%) and juniors (38\%). Of 78 responses, $62 \%$ never enrolled in an online course; $26 \%$ had taken one to three online courses; and $13 \%$ had taken more than three online courses.

The most commonly owned devices were smartphones (owned by $82 \% ; n=84$ )), notebook computers (owned by $74 \% ; n=84$ ), and desktop computer (owned by $23 \% ; n=84$ ). The devices usually used to connect to the Internet were smartphone (71\%), notebook (19\%), iPad (5\%), and computer (5\%). The respondents were asked about the frequencies they use a set of technologies (see Table 1). The most frequently used technologies were social media $(M=5.78)$, search engine $(M=5.75)$, web video $(M=5.49)$, and text chat $(M=5.33)$. The least frequently used technologies were blog $(M=3.05)$, voice chat $(M=3.32)$, video chat $(M=3.33)$, and wiki $(M=3.45)$.

\section{Acceptance of e-learning: construct validation}

The students reported their acceptance of e-learning by rating 18 statements on the 5-point Likert scale. The reliability of the scale was high (Cronbach's alpha $=.93$ ). Because we modified the 18 items on the acceptance scale, we performed a factor analysis to test for construct validity. The results showed three-factors solution (see Table 2). The items concerning image and two items of attitude loaded together on Factor 1. The items concerning compatibility loaded with other factors. All but one item of effort expectancy highly loaded on Factor 2. All but one item concerning performance expectancy loaded on Factor 3. Overall, the students' level of acceptance was only slightly more than neutral $(\mathrm{M}=3.05, \mathrm{SD}=.59)$.

Although the factor analysis suggested new latent constructs that were slightly different from the original constructs, each of the original constructs still had strong inter-item correlations $(p<.01)$. When they were tested for internal consistency, all but one obtained good reliability scores (Cronbach's alpha $\geq .80$ ). The only construct we believe was the weakest and should be analyzed with caution was compatibility (Cronbach's alpha $=.51$ ).

\section{Correlations}

A correlation coefficient was calculated to test relationships between variables. As shown in Table 3, strong positive correlations were found among constructs within the 
Table 1 Students' Familiarity with Technology

\begin{tabular}{|c|c|c|c|c|c|c|c|c|c|}
\hline & & & & (6) & (5) & (4) & (3) & (2) & (1) \\
\hline Tools/Technology & $n$ & Mean & SD & Every day & $\begin{array}{l}2-3 \text { times/ } \\
\text { week }\end{array}$ & $\begin{array}{l}\text { Once a } \\
\text { week }\end{array}$ & $\begin{array}{l}2-3 \text { times/ } \\
\text { month }\end{array}$ & $\begin{array}{l}2-3 \text { times } \\
\text { total }\end{array}$ & Never \\
\hline $\begin{array}{l}\text { Word processing } \\
\text { (e.g., MS Word) }\end{array}$ & 81 & 4.49 & 1.06 & $14 \%$ & $44 \%$ & $25 \%$ & $15 \%$ & $0 \%$ & $2 \%$ \\
\hline $\begin{array}{l}\text { Spreadsheet } \\
\text { (e.g., MS Excel) }\end{array}$ & 80 & 3.61 & 1.43 & $6 \%$ & $26 \%$ & $23 \%$ & $24 \%$ & $10 \%$ & $11 \%$ \\
\hline E-mail & 81 & 4.33 & 1.42 & $27 \%$ & $23 \%$ & $17 \%$ & $25 \%$ & $2 \%$ & $5 \%$ \\
\hline $\begin{array}{l}\text { Search Engine } \\
\text { (e.g., Google, Yahoo) }\end{array}$ & 79 & 5.75 & 0.67 & $84 \%$ & $11 \%$ & $1 \%$ & $4 \%$ & $0 \%$ & $0 \%$ \\
\hline Google Drive & 80 & 3.64 & 1.83 & $18 \%$ & $24 \%$ & $16 \%$ & $15 \%$ & $3 \%$ & $25 \%$ \\
\hline $\begin{array}{l}\text { Forums (e.g., } \\
\text { Pantip.com) }\end{array}$ & 77 & 3.78 & 2.00 & $27 \%$ & $21 \%$ & $12 \%$ & $12 \%$ & $0 \%$ & $29 \%$ \\
\hline Text chat (e.g., LINE) & 78 & 5.33 & 1.21 & $67 \%$ & $17 \%$ & $8 \%$ & $5 \%$ & $0 \%$ & $4 \%$ \\
\hline $\begin{array}{l}\text { Voice chat (e.g., } \\
\text { Google Hangout) }\end{array}$ & 78 & 3.32 & 1.98 & $15 \%$ & $24 \%$ & $12 \%$ & $12 \%$ & $0 \%$ & $37 \%$ \\
\hline Video chat (e.g., Skype) & 79 & 3.33 & 1.92 & $14 \%$ & $27 \%$ & $8 \%$ & $15 \%$ & $4 \%$ & $33 \%$ \\
\hline Computer games & 74 & 3.59 & 1.91 & $26 \%$ & $12 \%$ & $12 \%$ & $20 \%$ & $5 \%$ & $24 \%$ \\
\hline $\begin{array}{l}\text { Web Video } \\
\text { (e.g., YouTube) }\end{array}$ & 75 & 5.49 & 0.81 & $64 \%$ & $27 \%$ & $4 \%$ & $5 \%$ & $0 \%$ & $0 \%$ \\
\hline $\begin{array}{l}\text { Photo-focused } \\
\text { web (e.g., Instagram) }\end{array}$ & 78 & 4.37 & 1.74 & $35 \%$ & $23 \%$ & $21 \%$ & $3 \%$ & $5 \%$ & $14 \%$ \\
\hline $\begin{array}{l}\text { Blog (e.g., Blogger, } \\
\text { Blogspot) }\end{array}$ & 77 & 3.05 & 1.87 & $12 \%$ & $17 \%$ & $17 \%$ & $12 \%$ & $5 \%$ & $38 \%$ \\
\hline $\begin{array}{l}\text { Wikis (e.g., Wikipedia, } \\
\text { Wikispace) }\end{array}$ & 77 & 3.45 & 1.59 & $5 \%$ & $32 \%$ & $10 \%$ & $25 \%$ & $9 \%$ & $18 \%$ \\
\hline $\begin{array}{l}\text { Social Media (e.g., } \\
\text { Facebook, Twitter) }\end{array}$ & 78 & 5.78 & 0.62 & $86 \%$ & $9 \%$ & $3 \%$ & $3 \%$ & $0 \%$ & $0 \%$ \\
\hline
\end{tabular}

Means were calculated based on the scale from 1 (never) to 6 (everyday)

acceptance scale (items 1-6). Within the acceptance scale, the relationship between performance expectancy and effort expectancy was the strongest $(r=.75, p<.01)$. The weakest relationship was between social influence and performance expectancy $(r=.42$, $p<.01)$. All six constructs correlated highly with the overall acceptance of e-learning.

On average, students reported moderate level of self-regulation $(\mathrm{M}=3.49, \mathrm{SD}=.52)$. This self-regulation scale, however, had lower than acceptable level of internal consistency (Cronbach's alpha $=.63$ ). In particular, students tended to disagree with items related to image. They tended to disagree that people who take e-learning are getting better education $(\mathrm{M}=2.6, \mathrm{SD}=0.82)$; that people who take e-learning have good reputation $(\mathrm{M}=2.83, \mathrm{SD}=.83)$; that e-learning is good for their reputation $(\mathrm{M}=2.75 ; \mathrm{SD}=.75)$; and that students of e-learning are known and respected more than others $(\mathrm{M}=2.77 ; \mathrm{SD}=.75)$.

Self-regulation had small, positive correlation with performance expectancy $(r=.34$, $p<.01)$, effort expectancy $(r=.31, p<.01)$, compatibility $(r=.26, p<.05)$, and acceptance of e-learning $(r=.28, p<.05)$. School year showed similar results, with a small, positive correlation with acceptance of e-learning $(r=.25, p<.05)$. Lastly, negative correlations were found between the number of online courses taken and age $(r=-0.24$, $p<.05)$ as well as school year $(r=-0.26, p<.05)$. The familiarity with technology scale had no significant relationship with any other variables. 
Table 2 Rotated Component Matrix and Cronbach's Alpha of the Acceptance of e-learning Constructs

\begin{tabular}{|c|c|c|c|c|c|}
\hline \multirow[t]{2}{*}{ Constructs } & \multirow[t]{2}{*}{ Items } & \multirow[t]{2}{*}{ a } & \multicolumn{3}{|c|}{ Factors } \\
\hline & & & 1 & 2 & 3 \\
\hline \multirow{4}{*}{$\begin{array}{l}\text { Performance } \\
\text { Expectancy }\end{array}$} & E-learning would help me improve my academic performance. & \multirow[t]{4}{*}{0.80} & 0.25 & 0.75 & 0.22 \\
\hline & E-learning would allow me to do more work in less time. & & 0.15 & 0.38 & 0.66 \\
\hline & E-learning would make it easier to do my school work. & & -0.01 & 0.43 & 0.62 \\
\hline & E-learning will be useful for my career. & & 0.14 & 0.40 & 0.61 \\
\hline \multirow[t]{4}{*}{ Effort Expectancy } & Learning to use e-learning would be easy for me. & \multirow[t]{4}{*}{0.82} & 0.20 & 0.62 & 0.49 \\
\hline & I would find it easy to use e-learning without much help. & & 0.42 & 0.60 & 0.21 \\
\hline & It would be easy for me to become skillful at using e-learning. & & 0.23 & 0.68 & 0.39 \\
\hline & I would find e-learning easy to use. & & 0.29 & 0.16 & 0.74 \\
\hline \multirow[t]{3}{*}{ Attitude } & I think e-learning is a good idea for students. & \multirow[t]{3}{*}{0.80} & 0.63 & 0.24 & 0.54 \\
\hline & I think e-learning is a good idea for universities. & & 0.62 & 0.13 & 0.45 \\
\hline & I am interested in using e-learning. & & 0.38 & 0.02 & 0.68 \\
\hline \multirow[t]{4}{*}{ Image } & $\begin{array}{l}\text { I think that people who use e-learning are getting better } \\
\text { education than those who do not. }\end{array}$ & \multirow[t]{4}{*}{0.87} & 0.69 & 0.18 & 0.38 \\
\hline & I think that people who use e-learning have good reputation. & & 0.84 & 0.15 & 0.10 \\
\hline & Using e-learning is good for my reputation. & & 0.83 & 0.20 & 0.04 \\
\hline & $\begin{array}{l}\text { Students in my school who use e-learning are known and } \\
\text { respected more than others. }\end{array}$ & & 0.72 & 0.33 & 0.24 \\
\hline Social Influence & My parents will like it if I choose to enroll in an online class. & $\mathrm{n} / \mathrm{a}$ & 0.37 & 0.23 & 0.45 \\
\hline \multirow[t]{2}{*}{ Compatibility } & E-learning would allow me to learn what I want, when I want. & \multirow[t]{2}{*}{0.51} & 0.14 & 0.80 & 0.08 \\
\hline & I feel that e-learning is at least equal quality to classroom learning. & & 0.52 & 0.19 & 0.49 \\
\hline
\end{tabular}

\section{Discussion}

This study explores Thai students' level of acceptance for e-learning. The participants seemed to indicate that their acceptance of e-learning is only slightly more than neutral, which implies that Thai students tend to accept e-learning prudently. It is interesting to note that in two prior research studies both Siritongthaworn et al. (2006) and Teo, et al. (2011) found that the acceptance of e-learning was above average, and

Table 3 Pearson Correlations between Key Variables

\begin{tabular}{llllllllllll}
\hline & 1 & 2 & 3 & 4 & 5 & 6 & 7 & 8 & 9 & 10 & 11 \\
\hline 1. Performance Expectancy & 1 & & & & & & & & & \\
2. Effort Expectancy & $0.75^{* *}$ & 1 & & & & & & & & \\
3. Attitude & $0.59^{* *}$ & $0.71^{* *}$ & 1 & & & & & & & \\
4. Image & $0.56^{* *}$ & $0.64^{* *}$ & $0.72^{* *}$ & 1 & & & & & & \\
5. Social Influence & $0.42^{* *}$ & $0.53^{* *}$ & $0.57^{* *}$ & $0.47^{* *}$ & 1 & & & & & \\
6. Compatibility & $0.66^{* *}$ & $0.66^{* *}$ & $0.61^{* *}$ & $0.59^{* *}$ & $0.46^{* *}$ & 1 & & & & \\
7. Acceptance of e-learning & $0.84^{* *}$ & $0.90^{* *}$ & $0.86^{* *}$ & $0.83^{* *}$ & $0.63^{* *}$ & $0.79^{* *}$ & 1 & & & & \\
8. Self-Regulation & $0.34^{* *}$ & $0.31^{* *}$ & 0.13 & 0.12 & 0.21 & $0.26^{*}$ & $0.28^{*}$ & 1 & & & \\
9. Familiarity w Technology & 0.01 & 0.11 & 0.06 & -0.01 & 0.1 & 0 & 0.05 & 0.21 & 1 & & \\
10. Age & 0.11 & 0.03 & 0.06 & 0.08 & 0.1 & -0.06 & 0.07 & -0.14 & -0.08 & 1 & \\
11. Year in university & $0.22^{*}$ & $0.22^{*}$ & 0.16 & $0.3^{* *}$ & 0.15 & 0.08 & $0.25^{*}$ & -0.04 & -0.14 & $0.64^{* *}$ & 1 \\
12. Online classes taken & 0.03 & 0.1 & 0.13 & -0.01 & 0.2 & 0.11 & 0.09 & 0.03 & 0.1 & $-0.24^{*}$ & $-0.26^{*}$ \\
\hline
\end{tabular}

* Significant at $p<.05$, two-tailed

**Significant at $p<.01$, two-tailed 
the students who tended to adopt e-learning were younger students with technology skills. The results of the current study are different, which may be due to the focus of the current study is perceived consequences rather than uses and practices of current users of e-learning. The university branch where the research was conducted was experimenting with a synchronous course for the first time during the same time period when data was collected. It is also conceivable that a lower acceptance among the students is due to a lack of information leading to a lower knowledge of and experience with online education. Future research may seek to understand the nature of bridging apprehensive students who are inexperienced with e-learning uses and practices.

This current study found that performance expectancy and effort expectancy have a strong positive relationship and are strong indicators of technology acceptance, similar to prior research. These two factors also tend to vary in the same direction as attitude; in other words, the students who think that e-learning is useful and easy to use tend to also have positive attitudes toward e-learning. Social influence also appeared to have a positive relationship to perceptions and attitude, where social influence is operationalized as the approval from parents. Students who reported that their parents would be pleased to see them enrolled in an online course tend to also have positive attitude and perception toward e-learning.

The idea of approval extends into the construct of image, as it applies to social influence. For example, image is defined as the degree to which using e-learning is thought to enhance one's social status. Moore and Benbasat (1991) wrote that they considered image (or social status) one of the most important factors for innovation adoption. In Thailand's collectivistic, group-oriented work culture, the concern about one's image is even greater. Nevertheless, it is noteworthy that the average ratings of all the predictors of this construct are rather negative. In other words, the students tend to believe that e-learning does not enhance the user's reputation. The negative rating on image, therefore, may need to be further explored in future studies in order to understand the qualities of social status that could be influential when deciding to adopt e-learning within Thai culture.

One interesting finding was that the acceptance of e-learning is related to the students' school year. The students who are in a senior year tend to be more willing to accept e-learning. However, the results also reveal that despite their tendency to accept e-learning, these seniors took fewer online classes. Together, the relationships between some variables (age, number of online courses taken) suggest that older, senior-level students have taken fewer online classes; but they have a tendency to adopt e-learning more than younger, first-year students.

The study shows that Thai students show a positive relationship between acceptance of e-learning and self-regulation. Specifically, students who are more self-regulated also believe that online learning is useful and easy to use. This finding aligns with research that emphasizes self-regulation as a critical success factor for online students (Oliver, 2014). It is important to note, however, that one particular item on self-regulation was rated lower than others. This item did not correlate well and did not load with the rest of the items on the same scale when the factor analysis was performed. The item states, "As a student, I enjoy working independently." The distinctive responses to this item remind us that the Thai are accustomed to and prefer working in group (Pagram \& Pagram, 2006). While studying independently is usually discussed with self-regulation and learning autonomy, this statement may need to be modified when measuring self-regulation in the context of Thai culture. 
Indeed, it is quite reasonable for students to be highly self-regulated, and at the same time, work with others effectively. Another implication is that e-learning curricula in Thailand will need to include group work in order to be effective and suitable to the students.

This study reveals that the majority of students own smartphones and notebook computers, with only $23 \%$ of students owning a desktop computer. Moreover, smartphone is the top device the students use to connect to the Internet. These statistics support our prior knowledge that many Thai students do not have computer at home and often use computer at school. The findings also help us realize the high ownership rate of mobile devices, even in the more rural regions of Thailand. With regard to the use of technologies, the study shows that the students are very familiar with social media (Facebook, Twitter), search engines, web-video (e.g., YouTube), and text chat. They are less familiar with tools such as wiki, forum, video chat, and blog. These findings support most of the literature conducted in developing countries. The students are able to use basic software tools and they use the Internet, mostly for the purpose of web browsing, connecting with friends via chatting or Facebook, and watching YouTube videos.

The previous research on e-learning in developing countries contended that students' familiarity with computer and technology has an impact on the acceptance of e-learning. This study, however, shows no relationships between the familiarity with technology and the acceptance of e-learning or any of its constructs. It also reveals no relationships between the familiarity with technology and age, school year, self-regulation, or the number of online courses taken. As a result, we conclude that the students' decision to adopt e-learning is not contingent upon how familiar they are with related technology. In other words, students who are highly familiar with various types of technology may or may not have positive perception toward e-learning.

The results of this study offer a few practical implications to schools in Thailand, especially in the northeast region. First and foremost, if e-learning will be promoted, the schools may want to target junior or senior students. The schools need to improve students' perception about online education perhaps by educating them about its advantages, disadvantages, and requirements for success. Because the students currently hold that e-learning does not improve one's reputation, it may be more effective to have campaigns with alumni or students that are known, respected, and successful. If image is indeed one of the critical factors in the Thai culture, having testimonials from wellrespected individuals may increase the level of acceptance among students. Moreover, the schools will need to invest into proper technological training and support, especially for online collaborative tools with which students are unfamiliar. The collaborative tools like wiki, discussion forums, and chats may prove to be critical for students' success and satisfaction if the Thai prefer to study in group rather than independently. Finally, the schools have to equip the computer labs with sufficient computers and reliable Internet for students who do not own computers at home. Also, because most students own mobile devices, the e-learning platform may need to be mobile-friendly to accommodate students who may access online lessons using their smartphones.

\section{Limitations}

This study has provided meaningful information regarding e-learning acceptance, self-regulation, and technology use among students in the northeast region of 
Thailand. Yet, shortcomings were also discovered, mainly concerning the reliability of the scales. As previously stated, the scale of self-regulation has less than acceptable score for internal consistency. This suggests that the items will need to be revised or more items will need to be added to improve reliability.

The second limitation is with the items concerning the familiarity with technology. We believe that some items in this set may need further clarification. For instance, "Google Drive" is an item that students may interpret in a variety of ways. Google drive may refer to the use of a shared drive, or its feature that allows multiple users to collaborate on a single document. The items such as "Forum" and "Text chat" share several characteristics and can appear confusing to the respondents. Even though we provided examples for each technology item, we knew little about whether the examples apply well in the Thai context. Another concern is the use of technology familiarity scale. While the scale obtains an acceptable level of reliability (Cronbach's alpha $=.76$ ), we are aware that the scale includes quite a wide range of items - from word processing to social media tools. We recognize that, for example, one may be a heavy user of word processing, but may never use blog or wiki. As our results show, the mean of the familiarity with technology does not correlate with any other variables. We believe then that future research will obtain more meaningful data on this topic if these different technologies are better sorted out.

Next, the constructs of acceptance of e-learning scale can still be improved. As reported in the results section, the factor analysis shows that some items did not group well with the original constructs. In particular, the two items of the compatibility construct were not loaded together. One item loaded more closely with performance expectancy; the other appeared as a wild card as it did not strongly align itself with any of the constructs. Moore and Benbasat (1991), in fact, discovered a similar pattern. In their study, they found that the items for compatibility had high factor loading with the items measuring "relative advantage," which was highly related to performance expectancy. A modification or deletion of these items may be necessary in future research. Lastly, this study included only one item to measure social influence. Given the collectivistic culture, more items on social influence may improve the construct, and may allow us to learn even more about this aspect. Besides the parental influence, future studies may need to include other potential influencers such as teachers, peers, relatives, siblings, and employers.

These limitations on constructs are not uncommon to exploratory research studies. We hope that this study can serve as one of the pioneers that offers information on e-learning acceptance in Thailand using theoretically sound and reliable scale like UTAUT. We believe Thai schools and universities will benefit from this study and we hope to see more studies that explore this similar topic in different regions of the country.

Competing interests

Both authors declare that they have no competing interests.

Acknowledgements

We thank Supattraporn Saisomboon and Artchara Akkanit for assistance with data collection and translation of the survey.

Received: 31 March 2016 Accepted: 3 August 2016

Published online: 10 October 2016 
References

Adams, J. (2008). Understanding the factors that limit the acceptability of online courses and degrees. International Journal on E-Learning., 7, 4.

Addah, J. (2012). Computer literacy and E-learning: Attitudes among first year students in a Ghanaian medical school. International Journal of Computer Applications, 51, 22.

Akhu-Zaheya, L. M., Khater, W., Nasar, M., \& Khraisat, O. (2011). Baccalaureate nursing students' anxiety related computer literacry: a sample from Jordan. Journal of Research in Nursing, 18(1), 36-48.

Bediang, G., Stoll, B., Geissbuhler, A., Klohn, A., Stuckelberger, A., Nko'o, S., \& Chastonay, P. (2013). Computer literacy and E-learning perception in Cameroon: the case of Yaounde Faculty of Medicine and Biomedical Sciences. BMC Medical Education, 13, 57.

Bhuasiri, W., Xaymoungkhoun, O., Zo, H., Rho, J. J., \& Ciganek, A. P. (2012). Critical success factors for e-learning in developing countries: A comparative analysis between ICT experts and faculty. Computers \& Education, 58, 843-855.

Carsten, P., \& Temphairojana, P. (2013). Thailand's boom: To the northeast, the spoils. Reuters Business News, Downloaded May 22, 2015 from http://www.reuters.com/article/2013/06/16/us-thailand-northeastidUSBRE95F00H20130616.

Davis, F. D., Bagozzi, R. P., \& Warshaw, P. R. (1989). User acceptance of computer technology: A comparison of two theoretical models. Management Science, 35(8), 982-1003.

Decade 2020. (2015). Social Justice Part 1: Problems and Solutions in Thailand. Retrieved from http://decade2020.com/ problems-and-solutions-in-thailand.

Foley, J. A. (2005). English in...Thailand. Regional Language Centre Journal, 36(2), 223-234.

Folorunso, O., Ogunseye, O. S., \& Sharma, S. K. (2006). An exploratory study of the critical factors affecting the acceptability of e-learning in Nigerian universities. Information Management \& Computer Security, 14(5), 496-505.

Ikpe, I. B. (2011). E-learning platforms and humanities education: An African Case Study. International Journal of Humanities and Arts Computing, 5(1), 83-101.

Im, l., Hong, S., \& Kang, M. S. (2011). An international comparison of technology adoption Testing the UTAUT model. Information \& Management, 48, 1-8.

Iqbal, M. J., \& Ahmad, M. (2010). Enhancing quality of education through e-learning: The case study of Allama lqbal Open University. Turkish Online Journal of Distance Education, 11, 84-97.

Khaopa, Wannapa. (2012, November 26). Thailand could be major e-learning hub in region. The Nation. Retrieved from http://www.nationmultimedia.com/national/Thailand-could-be-major-e-learning-hub-in-region-30195003.html.

Kijsanayotina, B., Pannarunothaib, S., \& Speedie, S. M. (2009). Factors influencing health information technology adoption in Thailand's community health centers: Applying the UTAUT model. International Journal of Medical Informatics, 7(8), 404-416.

Lee, Y.-H., Hsieh, Y.-C., \& Hsu, C.-N. (2011). Adding Innovation Diffusion Theory to the Technology Acceptance Model: Supporting Employees' Intentions to use E-Learning Systems. Educational Technology \& Society, 14(4), $124-137$.

Moore, G. C., \& Benbasat, I. (1991). Development of an instrument to measure the perceptions of adopting an information technology innovation. Information Systems Research, 2, 192-222.

Oliver, M. (2014). Online learning helps prepare pupils for university. Education Journal, 218, 12-15.

Pagram, P., \& Pagram, J. (2006). Issues in e-learning: A Thai case study. The Electronic Journal of Information Systems in Developing Countries, 26(6), 1-8.

Pardamean, B., \& Susanto, M. (2012). Assessing User Acceptance toward Blog Technology Using the UTAUT Model. International Journal Of Mathematics And Computers In Simulation, 6(1), 203-212.

Park, S. Y. (2009). An analysis of the Technology Acceptance Model in understanding university students' behavioral intention to use e-learning. Educational Technology \& Society, 12(3), 150-162.

Pintrich, P. R. (2000). The role of goal orientation in self-regulated learning. In M. Beokaerts, P. R. Pintrich, \& M. Zeidner (Eds.), Handbook of self-regulation (pp. 452-502). New York: Academic.

Rogers, E. M. (1983). Diffusion of Innovations (3rd ed.). New York: Free Press.

Rueangprathum, A., Philuek, W., \& Fung, C. C. (2009). E-learning in Thailand - A survey of current situation and trend. Paper presented at the International Conference on Teacher Professional Development: Searching for New Paradigms, Agendas and Networks (ICONTPD 2009).

Saekow, A., \& Samson, D. (2011). E-learning readiness of Thailand's universities comparing to the USA's cases. International Journal of e-Education, e-Business, e-Management and e-Learning, 1(2).

Saengpassa, Chularat. (2013, December 2). E-learning slow to progress in Thailand. The Nation. Retrieved from http://www.nationmultimedia.com/national/E-Learning-slow-to-progress-in-Thailand-30221101.html.

Saowapon, C., Laohajaratsaeng, T., Thammajinda, R., \& Singharajwarapan, S. (2001). Education reform and e-learning in Thailand. Retrieved from http://www.oecd.org/education/skills-beyond-school/2428376.pdf.

Siritongthaworn, S., Krairit, D., Dimmitt, N. J., \& Paul, H. (2006). The study of e-learning technology implementation: A preliminary investigation of universities in Thailand. Education and Information Technologies, 11(2), 137-160. http://dx.doi.org/10.1007/s11134-006-7363-8.

Son, J., Robb, T., \& Charismiadji, I. (2011). Computer literacy and competency: A survey of Indonesian teachers of English as a foreign language. CALL-EJ, 12(1), 26-42.

Teo, T., Luan, W. S., Thammetar, T., \& Chattiwat, W. (2011). Assessing e-learning acceptance by university students in Thailand. Australasian Journal of Educational Technology, 27(Special issue, 8), 1356-1368.

Vate-U-Lan, P. (2007). Readiness of eLearning Connectivity in Thailand (Conference paper presented at the Fourth International Conference on elearning for Knowledge-based Society, November 18-19, Bangkok, Thailand).

Venkatesh, V., Morris, M. G., Davis, G. B., \& Davis, F. D. (2003). User acceptance of information technology: Toward a unified view. MIS Quarterly, 27, 425-478. 